\title{
DYNAMICS OF A LINK-TYPE INDEPENDENT ADAPTIVE EPIDEMIC MODEL
}

\author{
ANDRÁS SZABÓ-SOLTICZKY
}

\begin{abstract}
A link-type-independent adaptive network model of SIS epidemic propagation is considered. In the model links can be activated or deleted randomly regardless to the type of nodes. A four-variable pairwise ODE approximation is used to describe how the number of quantities such as number of infected nodes evolves in time. In order to investigate bifurcations in the model an invariant manifold is defined. Using the theory of asymptotically autonomous systems, results obtained for the reduced system on the manifold are extended to the full pairwise model and a non-oscillating behaviour is proven.
\end{abstract}

Mathematics subject classification (2010): 34C23, 37G10, 37N25, 92D30. Keywords and phrases: SIS epidemic, pairwise model, dynamic network.

\section{REFERENCES}

[1] C. Castillo-Chavez And B. Song, Dynamical models of tuberculosis and their applications, Math. Biosc. and Eng. 1, 361-404, 2004.

[2] T. Gross And B. Blasius, Adaptive coevolutionary networks: a review, J. Roy. Soc. Interface 5, 259-271, 2008.

[3] T. Gross, C. J. Dommar Dlima and B. Blasius, Epidemic dynamics on an adaptive network Phys. Rev. Lett. 96, 208701, 2006.

[4] J. K. Hale, Ordinary differential equations, Dover Publications, New York, 2009.

[5] T. House AND M. J. KeELING, Insights from unifying modern approximations to infections on networks, J. Roy. Soc. Interface 8, 67-73, 2011.

[6] D. Juher, J. Ripoll AND J. SAldAÑA, Outbreak analysis of an SIS epidemic model with rewiring, J. Math. Biol. 67, 411-432, 2013.

[7] M. J. Keeling, The effects of local spatial structure on epidemiological invasions, Proc. R. Soc. Lond. B 266, 859-867, 1999.

[8] I. Z. Kiss, L. Berthouze, T. J. TAYlor and P. L. Simon, Modelling approaches for simple dynamic networks and applications to disease transmission models, Proc. R. Soc. A. 468 (2141), 1332-1355, 2012.

[9] I. Z. Kiss, Joel C. Miller And P. L. Simon, Mathematics of network epidemics: from exact to approximate models, 2016.

[10] V. Marceau, P. A. Nö̈l, L. Hébert-Dufresne, A. Allard and L. J. Dubé, Adaptive networks: coevolution of disease and topology, Phys. Rev. E 82, 036116, 2010.

[11] S. Risau-Gusman AND D. H. ZanetTe, Contact switching as a control strategy for epidemic outbreaks, J. Theor. Biol. 257, 52-60, 2009.

[12] L. B. Shaw AND I. B. SchwartZ, Fluctuating epidemics on adaptive networks, Phys. Rev. E 77, 066101, 2008.

[13] A. Szabó-Solticzky, L. Berthouze, I. Z. Kiss and P. L. Simon, Oscillating epidemics in a dynamic network model: stochastic and mean-field analysis, Journal of Math. Biol., DOI 10.1007/s00285-015-0902-3, 2016.

[14] A. SZabó, P. L. Simon AND I. Z. Kiss, Detailed study of bifurcations in an epidemic model on a dynamic network, Differ. Equ. Appl. 4, 277-296, 2012. 
[15] H. R. ThIEME, Asymptotically autonomous differential equations in the plane, Rocky Mountain J. Math. 24, 351-380, 1994. 